\title{
Epidemiological Report on Outbreak Investigation of Chicken Pox in Muzaffarpur District, Bihar, India
}

\author{
Ragini Mishra \\ State Health Society, Bihar, India
}

Email address:

ragini330@gmail.com

To cite this article:

Ragini Mishra. Epidemiological Report on Outbreak Investigation of Chicken Pox in Muzaffarpur District, Bihar, India. Journal of Cancer Treatment and Research. Vol. 5, No. 3, 2017, pp. 28-38. doi: 10.11648/j.jctr.20170503.11

Received: October 12, 2016; Accepted: March 13, 2017; Published: March 27, 2017

\begin{abstract}
Chicken pox or varicella is an acute infectious disease of childhood caused by varicella-zoster virus (VZV), belonging to the family Herpesviridae. Outbreaks of Chicken Pox were reported in 10 blocks in Muzaffarpur district in Bihar from 16 Jan 2016 till 7 Feb 2016. Outbreak investigation was done in 3 blocks in the district to identify the reasons of outbreak and to suggest remedial measures for its control. Discussion with the District authorities and medical and paramedical staff was done to know the background information of the affected areas, genesis of outbreak, investigations carried out so far and control measures undertaken, visit to the affected areas was done and environmental investigation, knowledge, attitude \& practices of the community were also analyzed as per pre-planned questionnaire. Total 263 cases and 2 deaths due to Chicken Pox have been reported in Muzaffarpur from 10 blocks from Jan 2016 till Feb 7 2016. The disease afflicted almost all the age group but the incidence was more in the age group 1-14 years. Males were more affected than females in Block Mushahri and Meenapur while males and females are equally affected in Block Kurhani. The most common clinical manifestations observed were rash $(100 \%)$, fever $(88 \%)$ and headache $(24 \%)$. The rash was generalized in all of the cases, and the first site was the trunk in the majority $(60 \%)$ followed by face $(20 \%)$ of the patients. Majority $(54 \%)$ of the patients presented $51-100$ lesions followed by $25-50$ lesions $(52 \%)$. The history of contact with a case of chickenpox was available in all the patients while none of them gave a history of vaccination against VZV. Majority of the cases recovered spontaneously without any major complications. The area was overpopulated with residents living in poorly structured houses. Majority were living in a hut with entire family with poor ventilation facilities, which led to the spread of the virus. Majority of the affected population were illiterate (54\%) and unaware of the cause of the disease. The Health Workers viz: ASHAs and ANMs could play an important role in prevention of outbreak.
\end{abstract}

Keywords: Chicken Pox, Varicella-Zoster Virus, Outbreak

\section{Introduction}

Chicken pox or varicella is an acute infectious disease of childhood caused by varicella-zoster virus (VZV), belonging to the family Herpesviridae. [1] Human beings are the only known hosts of this virus. [2] The primary infection presents as fever and exanthematous rash but can affect almost any organ of the body. [3] The incubation period usually ranges between 7 and 23 days (mean- 2 weeks). The major route of transmission is airborne, however, transmissions via aerosols or direct contact with the blister fluid have also been reported. The disease is highly contagious with an attack rate of $>85 \%$ after exposure. A clinically apparent infection usually provides lifelong immunity. The disease is usually acute and self-limited but occasionally can lead to complications such as encephalitis, pneumonia, and secondary bacterial infections. Development of herpes zoster due to reactivation of latent varicella infection may be seen due to long-term consequences. [4]

Probable case definition used in Chicken Pox outbreak investigation was defined as an acute illness with diffuse (generalized) maculopapulovesicular rash, AND lack of laboratory confirmation, AND Lack of epidemiologic linkage to another probable or confirmed case. Confirmed case definition included an acute illness with diffuse (generalized) maculopapulovesicular rash, AND 
epidemiologic linkage to another probable or confirmed case, OR laboratory confirmation by VZV IgM \& IgG ELISA from blood samples.

In tropical regions, the disease preferably occurs during the cooler seasons such as winter and spring, and affects mainly adolescents and young adults. Tropical countries may be at a higher risk of morbidity and mortality due to the disease. $[5,6]$ The published data on the epidemiology of chicken pox in India is scarce as it was not a notifiable disease till 2005. Several on outbreaks of Chicken Pox has been reported in different parts of the world and in India. [7] The varicella vaccine is not a part of the Universal Immunisation Programme in India, hence outbreaks of chickenpox continue to occur in the naive unvaccinated rural population. $[8,9,10]$ Due to this, a progressive increase in seroprevalence with age has been found: maximum rates of seroconversion have been found in adolescents and adults [11]. Seasonality of Chicken Pox outbreaks has also been noted. [12] [13] The outbreak investigation was done to review and assess the situation of Chicken Pox outbreak in Muzaffarpur and to determine the causes of current outbreak, to conduct an epidemiological survey in some of the affected areas of Muzaffarpur, to assess the environmental and sociological factors contributing to the abundance of Chicken Pox cases, to assess the current situation by district wise analysis of Chicken Pox outbreak and to recommend remedial measures to overcome the current outbreak and prevent occurrence of outbreaks in future.

\section{Methodology}

Discussion with the District authorities and medical and paramedical staff to know the background information of the affected areas, genesis of outbreak, investigations carried out so far and control measures undertaken; Discussion with the physicians who treated the cases about the clinical presentation of cases, results of laboratory investigations and outcome of cases; Interview and clinical examination of some of the cases; Visit to affected areas; Rapid fever survey by house to house visit and collection of sera samples from suspected and confirmed cases for Chicken Pox confirmatory tests; Environmental investigation, knowledge, attitude \& practices of the community were also analyzed as per pre-planned questionnaire.

\section{Muzaffarpur District Profile}

Muzaffarpur district of Bihar is spread over an area of 3172 sq. kms. The district is bounded on the north by East Champaran and Sitamarhi districts, on the south by the district of Vaishali, on the east by the districts of Darbhanga and Samastipur (part) and on the west by Saran and part of Gopalganj districts. Important rivers include Bagmati, Gandak, Burhi Gandak \& Lakhandeye. Average rainfall is $1187 \mathrm{~cm}$ annually. The district has a population of 3.743 million (2001 census). Rural population in the district is $90.7 \%$ and urban population is $9.3 \%$. The density of the population was 929 per sq. kms. Literacy rate is $95 \%$. There are 2 Sub divisions, 16 Blocks, 387 Panchayats and 1811 villages.

\section{Epidemiological Observations and Results}

Is based on data collected from Integrated Disease Surveillance Programme (IDSP) reporting unit, their detailed analysis as well as questionnaire on clinical signs \& symptoms with the patients $\&$ their relatives as well as health officials.

Table 1. Block \& Panchayat wise distribution of Chicken Pox in Muzaffarpur (From 1 Jan 2016 till 9 Feb 2016.

\begin{tabular}{|c|c|c|c|c|c|c|}
\hline S.No. & Name of PHC & No of Cases & No of Deaths & Name of Affected Panchayat & & \\
\hline 1 & Aurai & 11 & 0 & Rajkhand, Bishtha & \multirow[b]{3}{*}{ Jhapahan, } & \multirow[b]{3}{*}{ Karanpur } \\
\hline 2 & Bandra & 0 & 0 & & & \\
\hline 3 & Bochahan & 12 & 0 & $\begin{array}{l}\text { Bhutane, } \\
\text { Uttari }\end{array}$ & & \\
\hline 4 & Gaighat & 0 & 0 & \multirow{3}{*}{ Pakri } & & \\
\hline 5 & Kanti & 6 & 0 & & & \\
\hline 6 & Katra & 0 & 0 & & & \\
\hline 7 & Kudhani & 42 & 0 & Pakahi, Sumera & & \\
\hline 8 & Marwan & 31 & 0 & \multirow{2}{*}{$\begin{array}{l}\text { Roopwara } \\
\text { Hajratpur }\end{array}$} & & \\
\hline 9 & Minapur & 22 & 0 & & & \\
\hline 10 & Motipur & 27 & 0 & \multirow[t]{2}{*}{ Sagahiyan Jauspur Mushar Tola } & & \\
\hline 11 & Muraul & 0 & 0 & & & \\
\hline 12 & Mushahari & 79 & 2 & \multirow[t]{3}{*}{ Narauli } & \multirow{8}{*}{$\begin{array}{l}\text { Birahi, Ambara } \\
\text { Basantpur, }\end{array}$} & \\
\hline 13 & Paroo & 0 & 0 & & & \multirow{7}{*}{$\begin{array}{l}\text { Tehari, } \\
\text { Gpinathpur }\end{array}$} \\
\hline 14 & Sahebganj & 0 & 0 & & & \\
\hline 15 & Sakra & 7 & 0 & \multirow{5}{*}{$\begin{array}{l}\text { Muriyari, Rajapakri } \\
\text { Chaki } \\
\text { Rawa } \\
\text { Dokra, Bahilwara Roopnath Uttari, } \\
\text { Basaitha, Gopi Dhanwat }\end{array}$} & & \\
\hline \multirow{4}{*}{16} & & & & & & \\
\hline & Saraiva & & & & & \\
\hline & Salarya & & & & & \\
\hline & Total & $\begin{array}{l}20 \\
263\end{array}$ & 2 & & & \\
\hline
\end{tabular}




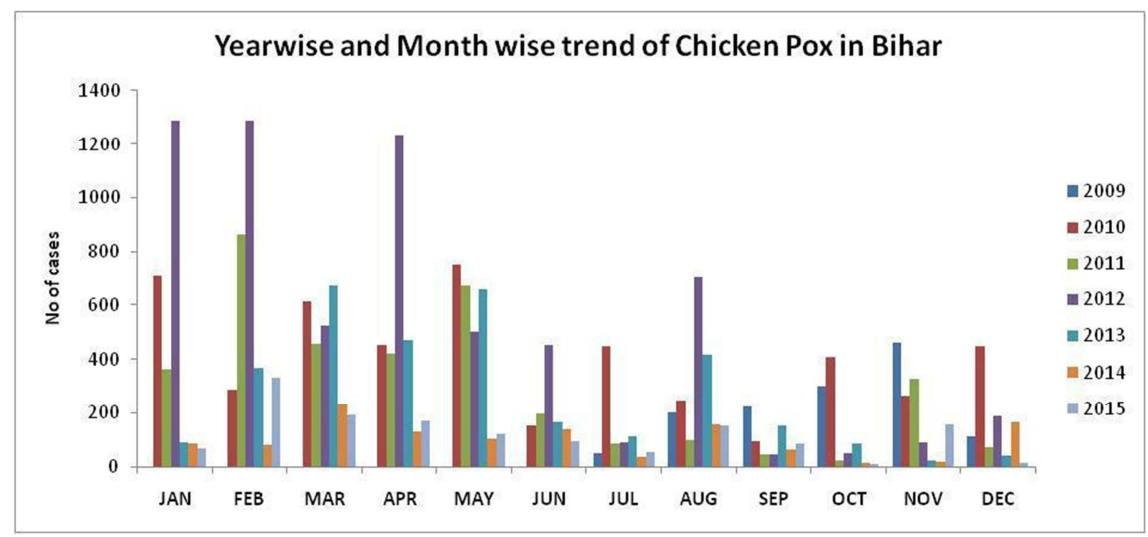

a) Year wise \& Month wise trend of Chicken Pox in Bihar (Based on presumptive surveillance)

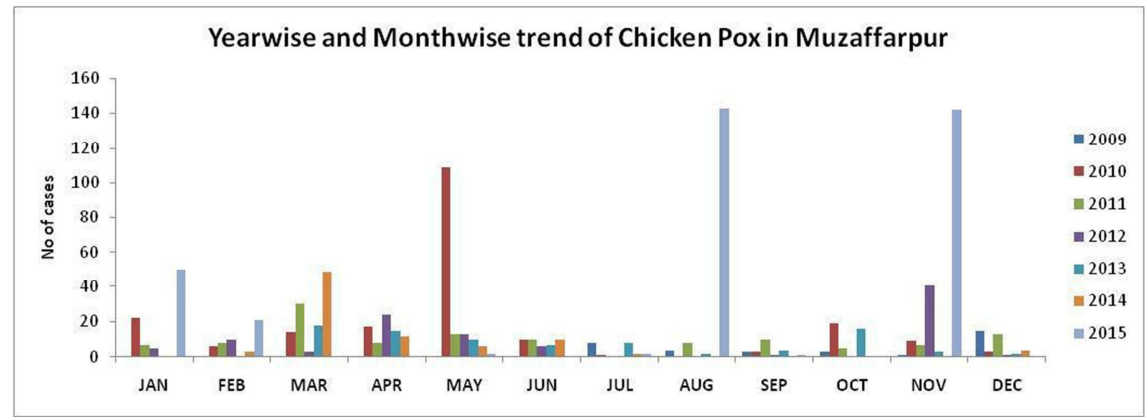

b) Year wise \& Month wise trend of Chicken Pox (Based on presumptive surveillance)

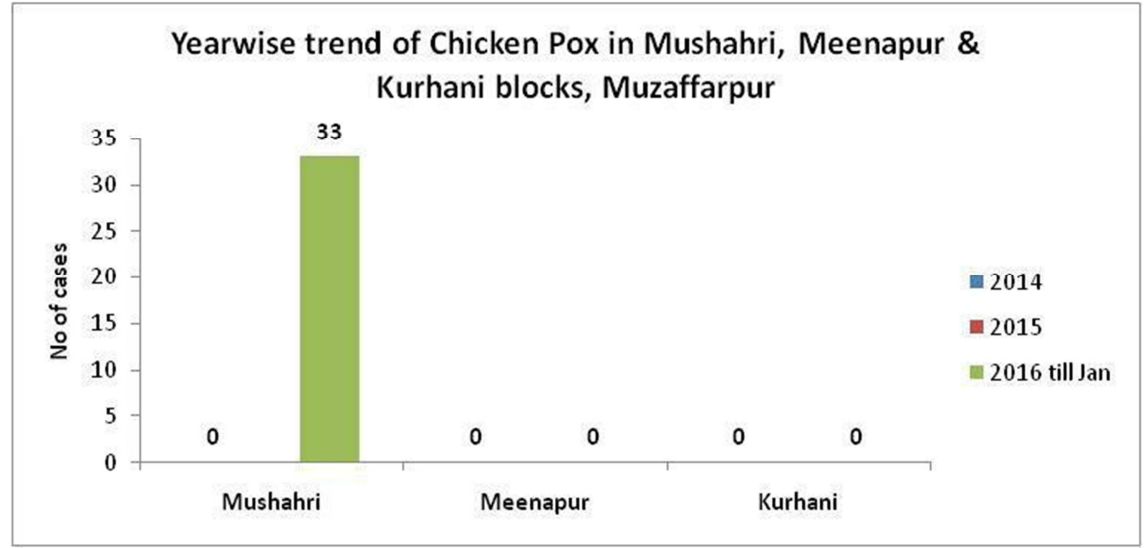

c) Yearly Epidemiological status of Chicken Pox in Mushahri, Meenapur \& Kurhani PHC

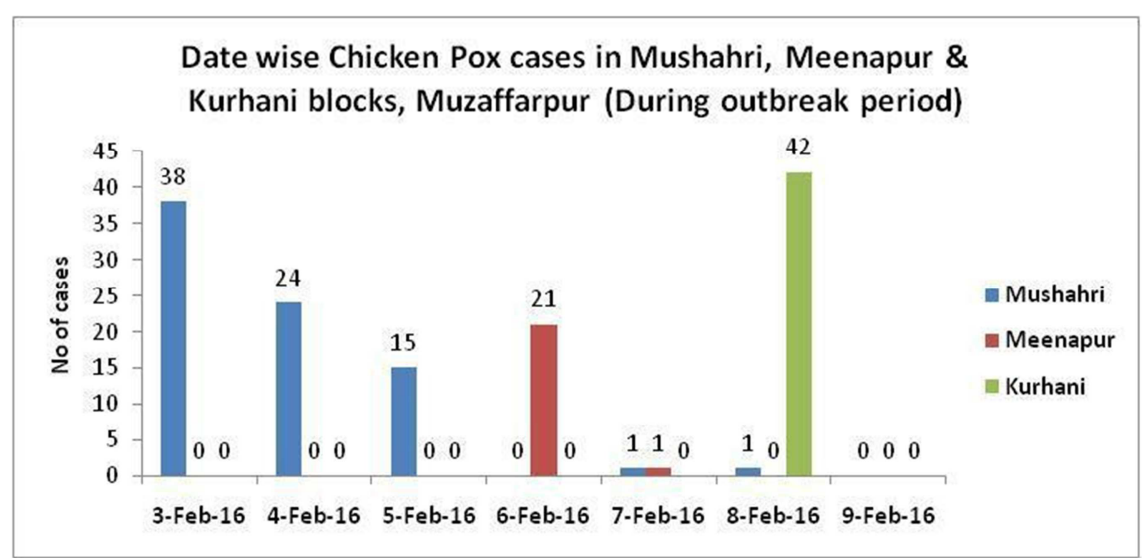

d) Date wise distribution of Chicken Pox cases in Block Mushahri, Meenapur \& Kurhani during outbreak period in 2016

Figure 1. Time wise distribution of Chicken Pox cases in Muzaffarpur. 
Table 2. Person wise distribution of Chicken Pox cases in Muzaffarpur.

\begin{tabular}{|c|c|c|c|c|c|c|c|c|c|}
\hline & \multicolumn{3}{|c|}{ Block Mushahri } & \multicolumn{3}{|c|}{ Block Meenapur } & & \multicolumn{2}{|c|}{ Block Kurhani } \\
\hline & \multicolumn{2}{|l|}{ Age } & \multicolumn{2}{|l|}{ Percentage } & & \multicolumn{2}{|l|}{ Percentage } & & Percentage \\
\hline & Group & Frequency & $(\%)$ & Age Group & Frequency & $(\%)$ & Age Group & Frequency & $(\%)$ \\
\hline $0-4$ & & 17 & 22 & $0-4$ & 7 & 32 & $0-4$ & 6 & 15 \\
\hline $5-9$ & & 22 & 28 & $5-9$ & 7 & 32 & $5-9$ & 11 & 26 \\
\hline $10-14$ & & 18 & 23 & $10-14$ & 3 & 14 & $10-14$ & 11 & 26 \\
\hline $15-19$ & & 12 & 15 & $15-19$ & 2 & 9 & $15-19$ & 3 & 7 \\
\hline $20-24$ & & 1 & 1 & $20-24$ & 1 & 4 & $20-24$ & 3 & 7 \\
\hline \multirow[t]{6}{*}{$25+$} & & 9 & 11 & $25+$ & 2 & 9 & $25+$ & 8 & 19 \\
\hline & Total & 79 & 100 & Total & 22 & 100 & Total & 42 & 100 \\
\hline & Sex & Frequency & $\begin{array}{l}\text { Percentage } \\
(\%)\end{array}$ & Sex & Frequency & $\begin{array}{l}\text { Percentage } \\
(\%)\end{array}$ & Sex & Frequency & $\begin{array}{l}\text { Percentage } \\
(\%)\end{array}$ \\
\hline & Male & 47 & 59 & Male & 12 & 55 & Male & 22 & 50 \\
\hline & Female & 32 & 41 & Female & 10 & 45 & Female & 22 & 50 \\
\hline & Total & 79 & 100 & Total & 22 & 100 & Total & 42 & \\
\hline
\end{tabular}

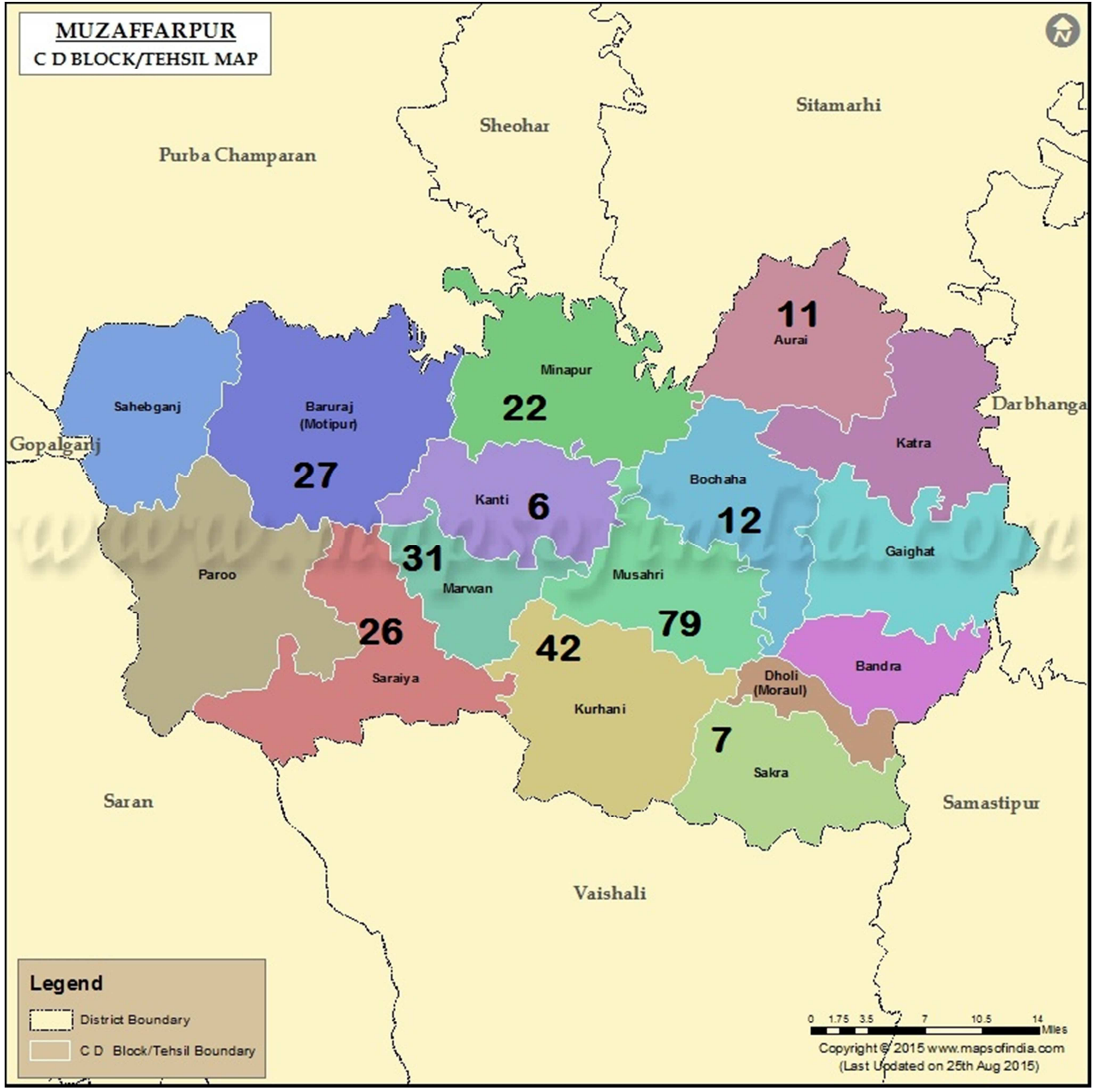

Figure 2. Place wise distribution of Chicken Pox in Muzaffarpur (From 1 Jan 2016 till 9 Feb 2016. 
Table 3. Serological status.

\begin{tabular}{llll}
\hline \multicolumn{2}{l}{ Serological status of blood samples tested for Chicken Pox confirmation in Muzaffarpur } & & VZV \\
\hline Block & No of samples & VZV IgM ELISA Positive & ELISA \\
\hline & & & Positive \\
\hline Mushahri & 4 & 4 & 2 \\
Meenapur & 7 & 7 & 0 \\
Kurhani & 5 & 5 & 0 \\
Total & 16 & 16 & 2 \\
\hline
\end{tabular}

\section{Environmental and Sociological Observations and Results}

These are based on standard pre-planned questionnaire \& interview with the patients \& their relatives as well as community members residing in visited villages.

Table 4. Knowledge, Attitude and Practices of affected community.

\begin{tabular}{|c|c|c|}
\hline \multicolumn{3}{|c|}{ Knowledge, Attitude \& Practices in affected population } \\
\hline \multirow[b]{2}{*}{ Characteristics } & \multicolumn{2}{|c|}{ No. $(\mathrm{N}=50)$ (includes combined figures of } \\
\hline & village Naraulidih & (Mushahri), Hazrathpur \\
\hline & \multicolumn{2}{|c|}{ (Meenapur) \& Pakahi (Kurhani)) } \\
\hline Educational status & No. & $\%$ \\
\hline Illiterate & 27 & 54 \\
\hline Up to primary & 16 & 32 \\
\hline $\mathrm{Up}$ to $\mathrm{SSC}$ & 5 & 10 \\
\hline Up to HSC \& above & 2 & 4 \\
\hline \multicolumn{3}{|c|}{ Symptoms of Chicken Pox narrated } \\
\hline Fever & 44 & 88 \\
\hline Rash & 50 & 100 \\
\hline Headache & 29 & 58 \\
\hline Tiredness & 12 & 24 \\
\hline Malaise & 4 & 8 \\
\hline Loss of appetite & 10 & 20 \\
\hline $1^{\text {st }}$ site of rash (a) Trunk & 30 & 60 \\
\hline (b) Face & 10 & 20 \\
\hline (c) Head and Forehead & 5 & 10 \\
\hline (d) Mouth & 2 & 4 \\
\hline (d) other parts of body & 3 & 6 \\
\hline No of lesions $(25-50)$ & 16 & 32 \\
\hline$(51-100)$ & 17 & 34 \\
\hline$(100-150)$ & 10 & 20 \\
\hline$(150-200)$ & 5 & 10 \\
\hline$(200-250)$ & 2 & 4 \\
\hline \multicolumn{3}{|l|}{ Treatment seeking } \\
\hline Government agency & 20 & 40 \\
\hline Private agency & 15 & 30 \\
\hline Quack & 10 & 20 \\
\hline Chemist & 5 & 10 \\
\hline \multicolumn{3}{|l|}{ Hospitalization } \\
\hline No & 47 & 94 \\
\hline Yes & 2 & 4 \\
\hline \multicolumn{3}{|c|}{$\begin{array}{l}\text { Anti Chicken Pox measures adopted viz: Sanitation, personal hygiene, } \\
\text { isolation et }\end{array}$} \\
\hline Yes & 15 & 30 \\
\hline No & 35 & 70 \\
\hline \multicolumn{3}{|c|}{ Reason for not using anti Chicken Pox measures $(\mathrm{N}=35)$} \\
\hline Economical & 20 & 57 \\
\hline Do not know & 10 & 29 \\
\hline Do not care & 5 & 14 \\
\hline
\end{tabular}

\section{Results and Discussion}

Total 263 cases and 2 deaths due to Chicken Pox were reported in Muzaffarpur from 10 blocks from Jan 2016 till Feb 7 2016. 3 blocks viz Meenapur, Mushahri and Kurhani were visited for outbreak investigation. Mushahri was the most affected block with 79 cases $>$ Kurhani (42 cases) $>$ Meenapur ( 22 cases). 47 cases of Chicken Pox was reported by the district in Jan 2016 in Presumptive Surveillance Form, IDSP. However, in affected PHCs that were visited, cases were not reported in Presumptive Form on weekly basis but 79 cases were reported at once between $3^{\text {rd }}$ and $5^{\text {th }}$ Feb 2016 from Mushahri followed by 22 cases from Meenapur between $6^{\text {th }} \& 7^{\text {th }} \mathrm{Feb} 2016$ and 42 cases from Kurhani on $8^{\text {th }} \mathrm{Feb} 2016$. On verification, it was found that index case in Mushahri, Meenapur and Kurhani occurred on $5^{\text {th }}, 7^{\text {th }} \& 8^{\text {th }}$ Jan 2016 respectively. In Mushahri, index case was a male child aged 10 years who spread the disease to few other school mates belonging to same area. Index case from Meenapur was again a male child aged 8 years who spread the disease first among the siblings and then in nearby community. Index case in Kurhani was a girl child aged 12 years, who spread the infection to home-mates and then to others in community. Cases were occurring in spurt and in clusters and many had already healed that were not reported. 2 deaths were also reported in Mushahri block. On verification, it was found that a boy that died, aged 17 years was suffering from Liver cirrhosis since last 3 years. Before his death he suffered from Chicken Pox, his brother and father were also affected with Chicken Pox. Another deceased was a girl child aged 20 days. As per communication with her mother, she suffered from Chicken Pox and died. Girl was residing with maternal uncle, mother and grandmother. Her mother and uncle was also suffering from Chicken Pox. No documents to verify death were available as the same were buried by the family members but since the epidemiological linkage is strong enough the two deaths can be presumed to be due to Chicken Pox. 16 samples that included 7, 4 and 5 samples from suspected cases in Meenapur, Mushahri and Kurhani blocks respectively were collected for lab confirmation. All samples were confirmed in IDSP PMCH, Microbiology Lab. All samples were VZV IgM ELISA positive. The disease afflicted almost all the age group but the incidence was more in the age group 1-14 years in all the 3 blocks. Males were more affected than females in Block Mushahri and Meenapur while males and females were equally affected in Block 
Kurhani. The most common clinical manifestations observed were rash $(100 \%)$, fever $(88 \%)$ and headache $(24 \%)$. The rash was generalized in all of the cases, and the first site was the trunk in the majority $(60 \%)$ followed by face $(20 \%)$ of the patients. Majority (54\%) of the patients presented 51-100 lesions followed by $25-50$ lesions (52\%). The history of contact with a case of chickenpox was available in all the patients while none of them gave a history of vaccination against VZV. Majority of the cases recovered spontaneously without any major complications. History of travel outside the locality was insignificant during the field visit. The general weather condition during the last one month has been cold favouring the disease transmission. Based on analysis of past data under IDSP, the disease incidence is actually more from Jan till April in the State indicating seasonality of occurrence. The area was overpopulated with residents living in poorly structured houses. Majority were living in a hut with entire family with poor ventilation facilities, which led to the spread of the virus.

Most of the affected population belonged to low socioeconomic strata, with most of the houses being semi -pucca/ or mud-plastered category. Majority of them belonged to agricultural labour community. Majority were living with family in single hut with no proper ventilation, so disease transmission was very rapid. The cases belonged to Harijan tola, Manjhi tola and Muslim tola in Mushahri, Meenapur and Kurhani blocks respectively.

Majority of the affected population were illiterate (54\%) and unaware of the cause of the disease. $40 \%$ of the cases seeked treatment in Govt. institutions while 30\% \& $20 \%$ cases seeked treatment in private institutions and through quacks respectively. $94 \%$ of the cases did not require hospitalization while $4 \%$ seeked hospitalizations on account of co-morbid conditions. $70 \%$ of the affected population did not take anti-Chicken Pox measures. About $57 \%$ of the cases informed economical reasons to be the main cause of not adopting anti-Chicken Pox measures. Many people did not report about the cases in their family to the Health Workers on religious ground on account of unawareness. Most of the affected areas were very dirty \& no proper waste management was being done. The study is expected to provide evidence on the factors responsible for Chicken Pox outbreaks and to plan for appropriate interventions to prevent any future impending disease outbreaks.

\section{Conclusion}

Total 263 cases and 2 deaths due to Chicken Pox were reported in Muzaffarpur from 10 blocks from Jan 2016 till Feb 7 2016. Out of 3 blocks visited, Mushahri was the most affected block with 79 cases $>$ Kurhani (42 cases) $>$ Meenapur (22 cases).16 blood samples were collected from suspected cases from 3 blocks for Chicken Pox lab confirmation in Patna Medical College and Hospital (PMCH, Patna). All 16 samples were IGM ELISA positive. Cases were occurring in clusters since first week of Jan 2016 but were not being reported on weekly basis. They were reported at once to the higher authorities in February when large number of cases was seen including 2 deaths. On verification, it was found that index case in Mushahri, Meenapur and Kurhani occurred on $5^{\text {th }}, 7^{\text {th }} \& 8^{\text {th }}$ Jan 2016 respectively, delay in reporting of index cases to the higher authorities and adopting no control measures at the right time led to the rapid transmission of the disease. The incidence of the disease was more in age group $1-15$. Majority of the affected cases showed rash (100\%) as the most common symptom followed by fever $(88 \%)$. Majority of the affected population were illiterate (54\%) and residing in a small hut with family that had no proper ventilation which led to rapid transmission of the disease. $70 \%$ of the affected population did not adopt any sanitary and personal hygiene measures that also contributed for the spread of the disease outbreak. Few families were observed to apply ghee or burnt ashes on rashes and blisters of the cases in the affected areas on account of ignorance. The Health Workers viz: ASHA and ANMs although were visiting the houses in their allotted areas on regular basis, were not sensitized on the threshold of the disease and importance of timely reporting. They could play a vital role in accurate and timely reporting to health authorities, thus leading to early interventions and control of outbreaks.

\section{Recommendations}

- Strengthening of the surveillance, particularly fever and rash along with appropriate response.

- Health Workers viz: ASHAs and ANMs should be informed to keep a close vigil on fever and rash cases in their respective areas, ensure its reporting to higher authorities on regular basis and also refer them to the nearest health facility for early diagnosis and prompt treatment.

- Sensitization of medical and para-medical personnel in the government as well as private sectors needs to be undertaken for trigger level of the disease and for appropriate and timely management of cases.

- Ensure that the cases of Chicken Pox are reported on weekly basis in Presumptive Surveillance Form of IDSP from all Reporting Units. Any outbreak ( $>3$ cases in a locality at a particular time) should be informed by the MoICs in Early Warning Signal Form under IDSP. Daily reporting to the State Surveillance Unit should be done in case of outbreak.

- Ensure active surveillance in the affected areas for at least 42 days for each reported case to prevent further transmission of the disease assuming the incubation period of the disease (10-21 days on an average).

- Ensuring complete symptomatic treatment to all cases. Homeopathic medicines may be provided to susceptible individuals in affected areas. RKS fund may be utilized for purchasing the same.

- District level coordination meeting comprising of local community leaders of affected areas and other stakeholders should be called to spread awareness regarding the disease and to prevent future outbreaks by 
building community awareness.

- Medical camps in affected areas would be beneficial as this would also ensure community awareness regarding prevention and control of the disease outbreak.

- Awareness of Community through IEC, IPC \& BCC must be done for success of intervention methods. This should cover following aspects:

A) Cause and transmission of Chicken Pox, about the sources of transmission, treatment, isolation of cases and community measures for adopting sanitary and personal hygiene measures like washing the clothes with boiled water, keeping the surroundings clean, cutting the finger nails of kids to avoid scratching of scabs and further infections.

B) Spread of awareness among risks groups like infants, adolescents, adults, pregnant women and people with weakened immune system because of illness or medication or other co-morbid conditions for taking special precautions for the prevention and control of the disease.

- All places adjoining the affected areas where Chicken
Pox cases/outbreak have been recorded should be made alert and close vigil on all the fever and rash cases should be kept for early recognition of cases and their timely referral for cases management to prevent further future outbreaks.

- Availability of drugs both allopathic and homeopathic, topical lotions, Vit A, Iron Folic Acid etc should be ensured at all the Health facility for prompt treatment.

- Providing homeopathic drugs as a preventive measure to susceptible population in affected areas especially children under 15 years. In additions Acyclovir may also be provided as per need and protocol.

- Waste management should be properly planned by District Health Authorities

\section{Acknowledgements}

The Author is thankful to Secretary Health-Cum-Executive Director, State Health Society, Bihar for his valuable support. The Author is also thankful to District Officials, Muzaffarpur for providing support to carry out field investigation.

\section{Appendix: Photographs of Field Visit}

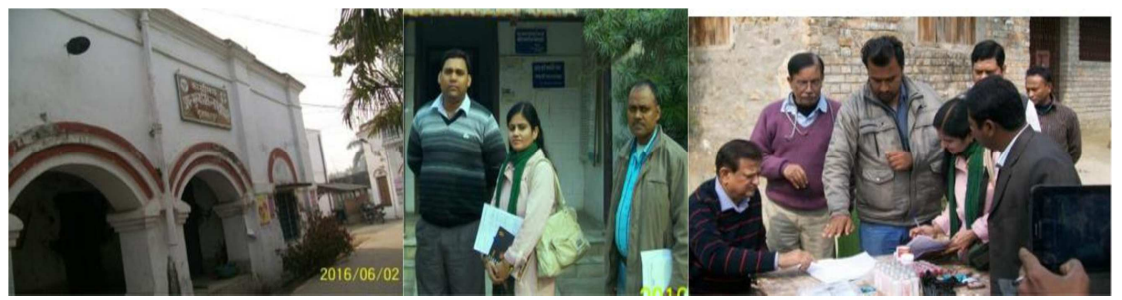

Figure A1. FieldvisitPicsforCHKPoxoutbreakinvestigationinMuzaffarpurdistrict.

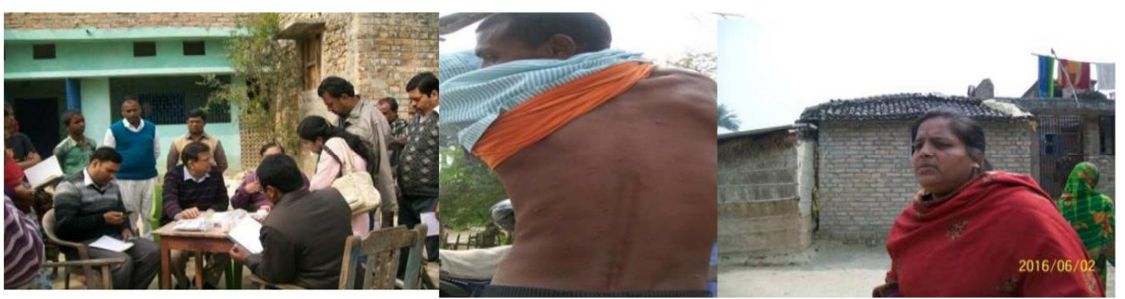

Figure A2. Interaction with Health Officials \& Community interaction in HazrathpurVillage: PHCMinapur.

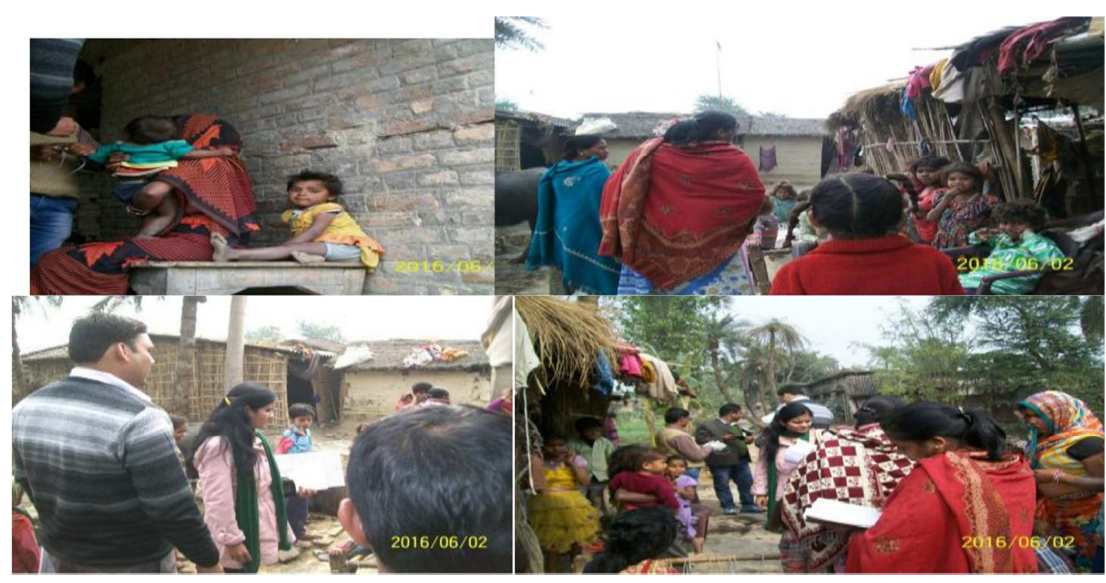

Figure A3. Sample collection at Hazrathpur Village: PHC Minapur \& Socio-economic condition in Village Hazrathpur, Harijantola. 


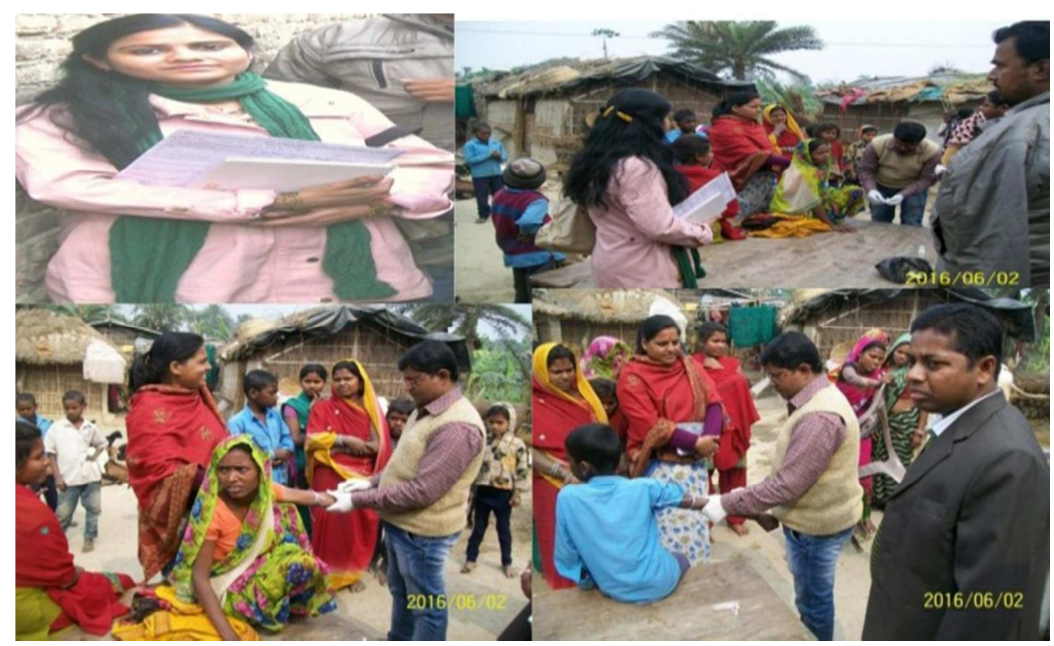

Figure A4. Samplecollection\&communityinteractioninVillageHazrathpur, PHCMinapur.

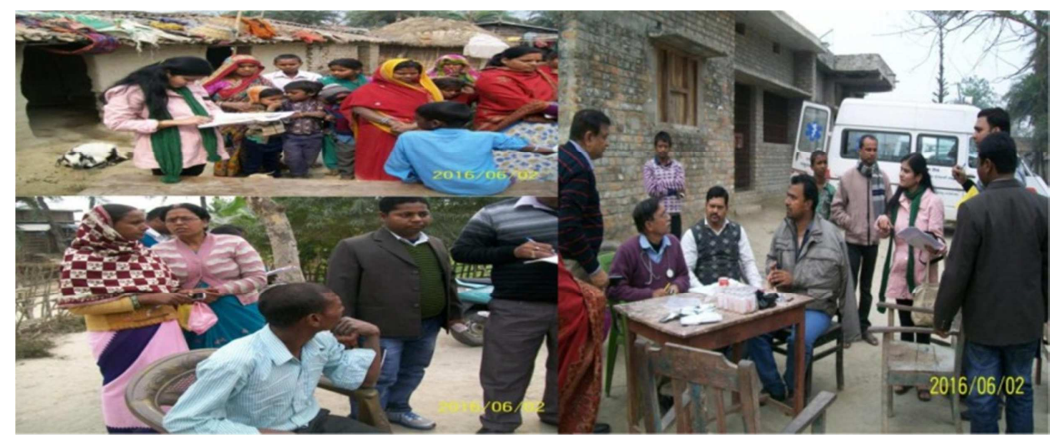

Figure A5. Verification of the immunization status against VPDs in community in Village Hazrathpur; Harijantola; PHC Minapur.

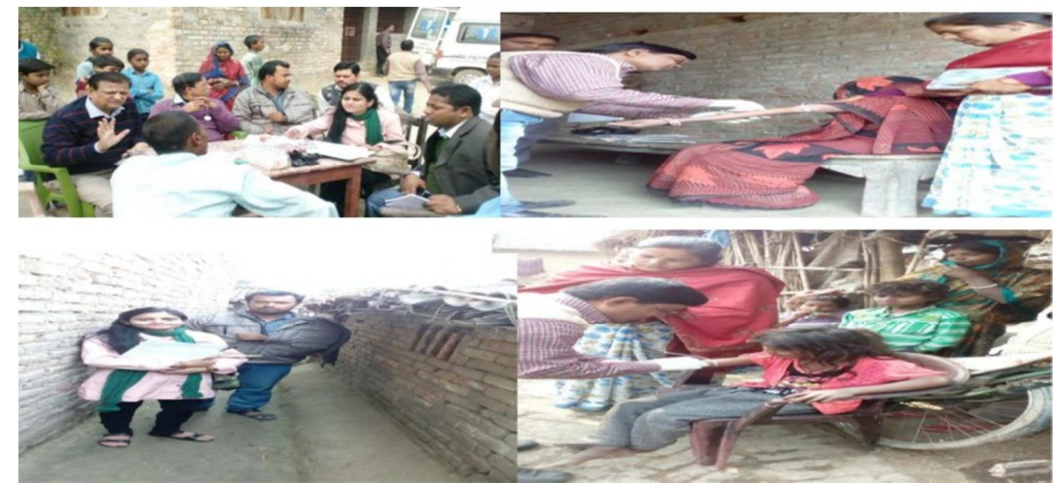

Figure A6. Interaction with cases, active case search \& sample collection in Village Hazrathpur; Harijantola; PHC Minapur.

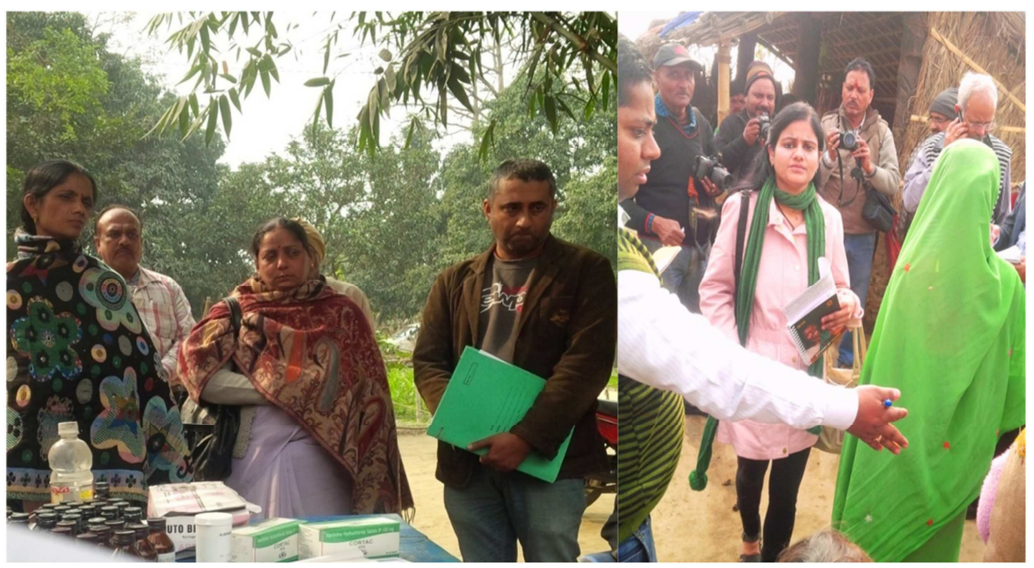

Figure A7. Interaction with ANM, ASHA \&community members, sample collection in Village Narauli Dih; PHC Mushari. 


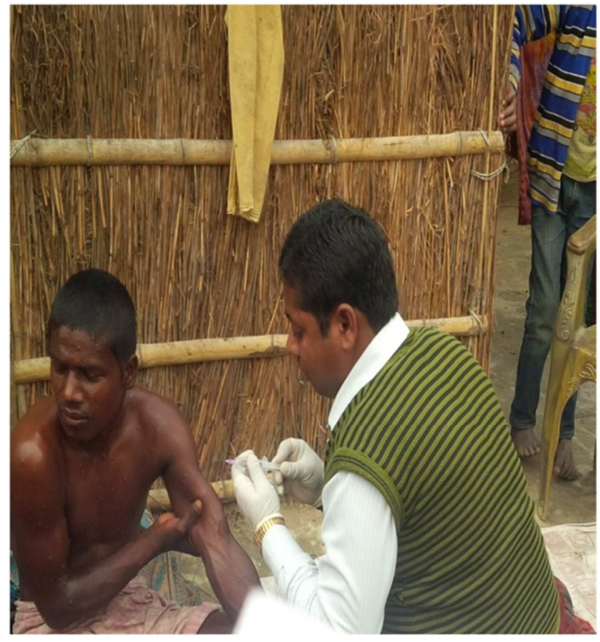

Figure A8. Case with 500 lesions.

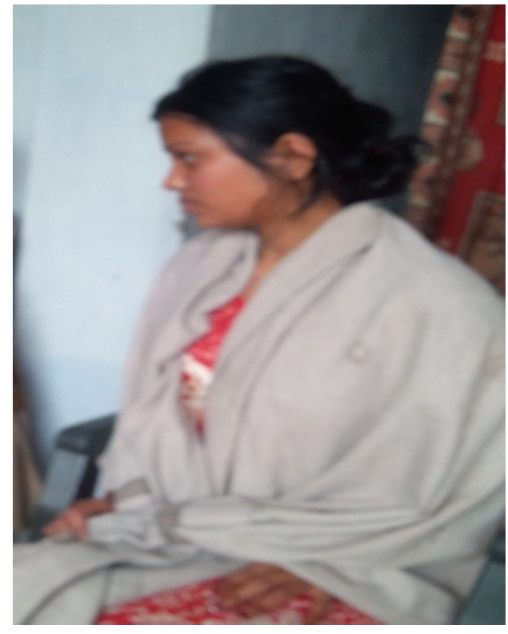

Figure A9. Case suffering from CHK Pox had previous history of CHK Pox at age 7years, Vill: Narauli Dih: Repeated occurrence.

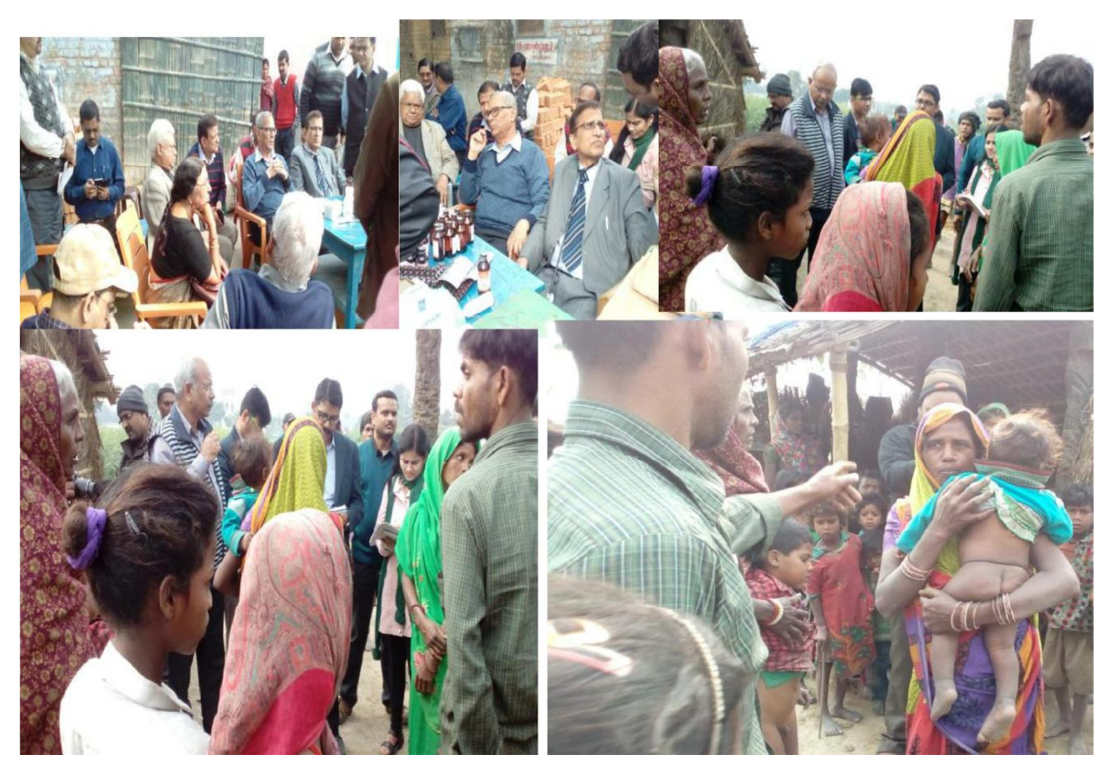

Figure A10. Interaction with Health Workers and Community members at Village: Narauli Dih, PHC Mushari.

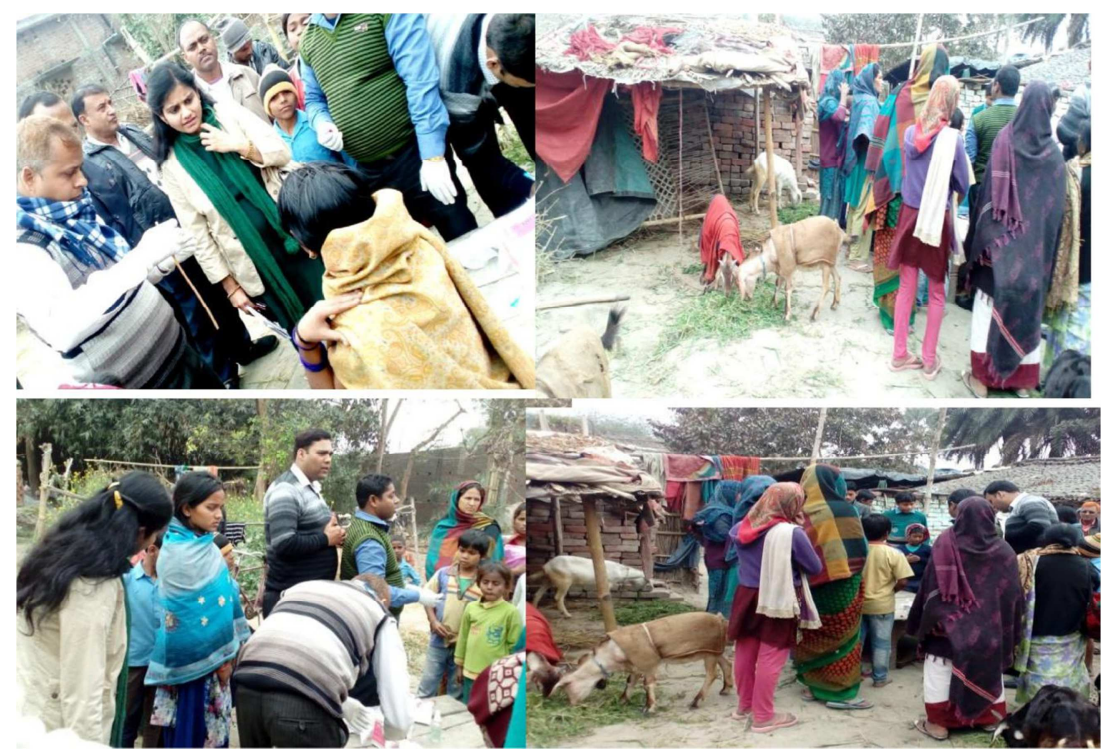

Figure A11. Interaction with Health Workers and Community members \&socio-economic conditions in Village: Pakahi, PHC Kurhani. 


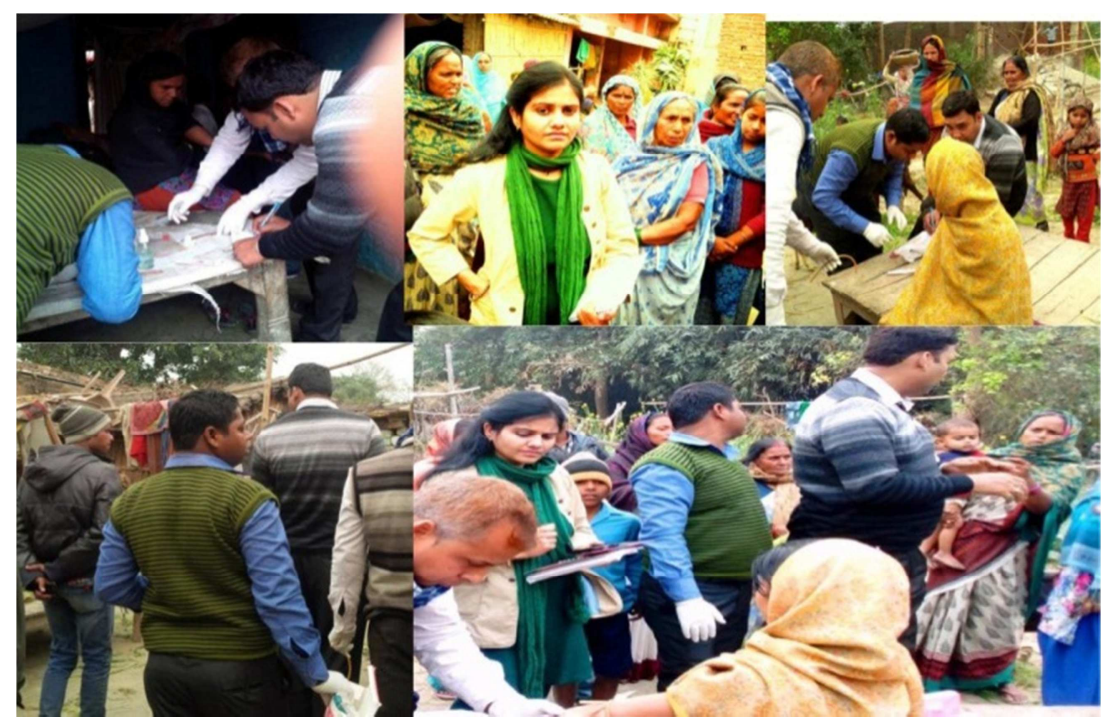

Figure A12. Sample collection, community interaction in Village Pakahi, PHC Kurhani.

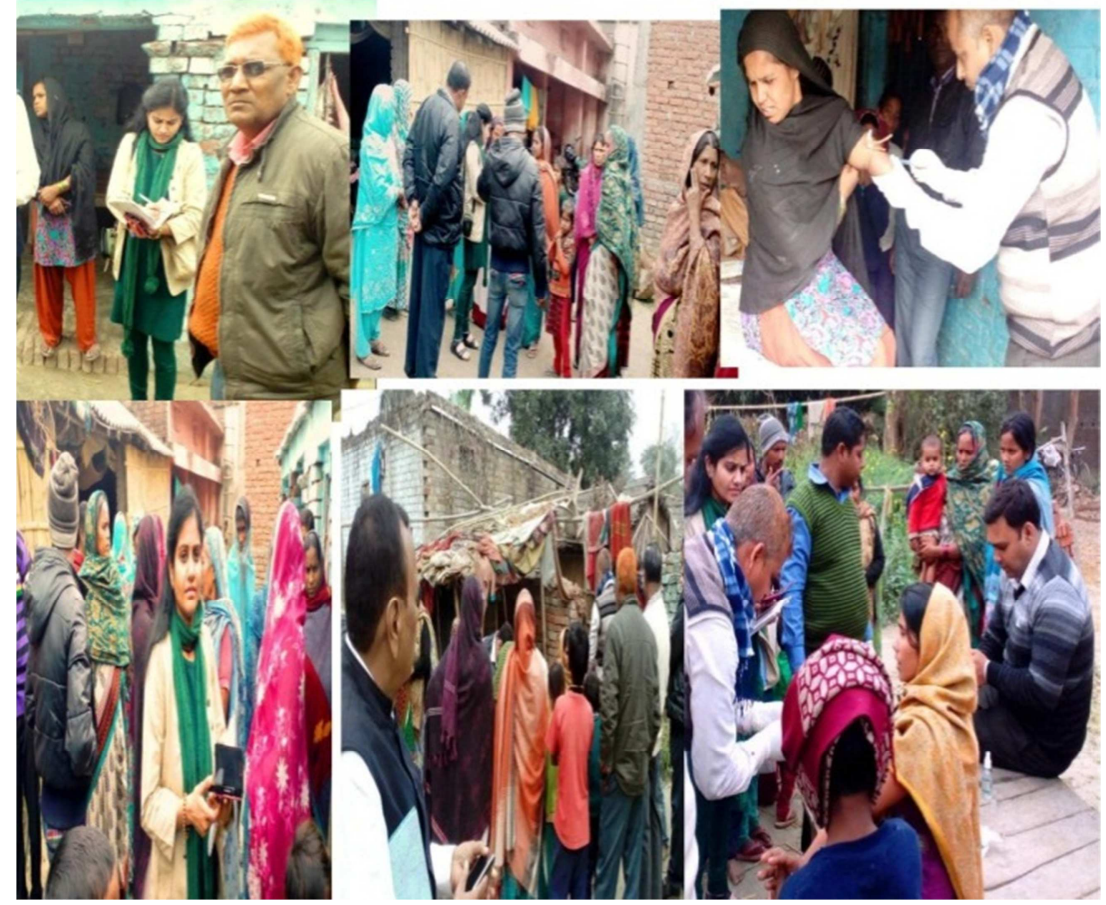

Figure A13. Socio-economicconditions, sample collection \&community interaction in vill Pakahi, PHC Kurhani.

\section{References}

[1] Arvin AM. Varicella-zoster virus. Clin Microbiol Rev 1996; 9: 361-81.

[2] Ozaki T, Kajita Y, Namazue J, Yamanishi K. Isolation of varicella-zoster virus from vesicles in children with varicella. J Med Virol 1996; 48: 326-8.

[3] Tabak F, Murtezaoglu A, Tabak O, et al. Clinical features and etiology of adult patients with fever and rash. Ann Dermatol. 2012; 24 (4): 420-5

[4] Nagel MA, Gilden D. Complications of varicella zoster virus reactivation. Curr Treat Options Neurol 2013; 15: 439-53
[5] Guess HA, Broughton DD, Melton LJ $3^{\text {rd }}$, Kurland LT. Population-based studies of varicella complications. Pediatrics 1986; 78: 723-7.

[6] Baren JM, Henneman PL, Lewis RJ. Primary varicella in adults: Pneumonia, pregnancy, and hospital admission. Ann Emerg Med 1996; 28: 165-9.

[7] Tugwell BD, Lee LE, Hilary G, Lorber EM, Hedberg K, Cieslak PR. Chickenpox outbreak in a highly vaccinated school population. Pediatrics. 2004; 113:.455.

[8] Verma R, Bairwa M, Chawla S, Prinja S, Rajput M. Should the chickenpox vaccine be included in the National Immunization Schedule in India? Hum Vaccin 2011; 7: 874-7

[9] Sinha DP. Chickenpox - A disease predominantly affecting adults in rural West Bengal, India. Int J Epidemiol 1976; 5: 367-74. 
[10] Balraj V, John TJ. An epidemic of varicella in rural southern India. J Trop Med Hyg 1994; 97: 113-6.

[11] Lee BW. Review of varicella zoster seroepidemiology in India and SoutheEast Asia. Trop Med Int Health. 1998; 3 (11): 886890.

[12] Kevin M. Bakkera, Micaela Elvira Martinez-Bakkerc, Barbara
Helmd, and Tyler J. Stevensone-Digital epidemiology reveals global childhood disease seasonality and the effects of immunization. PNAS. 2016; vol 113, 6689-6694.

[13] Wayne P. London and James A. Yorke- Recurrent outbreaks of Measles, Chicken Pox and Mumps: Seasonal variation in contact rates. American Journal of Epidemiology; Vol 98, 453-468. 